\title{
SIMILITUDES Y DIFERENCIAS ESTRATIGRÁFICAS ENTRE EL PRIDOLIENSE-PRAGUIENSE CELTIBÉRICO Y ARMORICANO
}

\author{
Peter CARLS y José Ignacio VALENZUELA-RÍOS ${ }^{2}$ \\ ' Institut für Geowissenschaften, Technische Universität Braunschweig, Pockels-Str. 3, D - \\ 38106 Braunschweig (Alemania). \\ ${ }^{2}$ Departamento de Geología, Universitat de València, c/. Dr. Moliner 50, E-46100 Burjassot, \\ València. E-mail: Jose.I.Valenzuela@uv.es
}

\begin{abstract}
Carls, P. y Valenzuela-Ríos, J.I. 1999. Similitudes y diferencias estratigráficas entre el Pridoliense-Praguiense celtibérico y armoricano.[Pridolian-Pragian stratigraphic similarities and differences in Celtiberia and Armorica.] Revista isspañola de Paleontología, 14(2), 279-292. ISSN 0213-6937.
\end{abstract}

Dedicamos este trabajo al Prof. Dr. Jaime Truyols Santonja con veneración y gratitud por su legado científico, personal y por la creación de la estupenda escuela de Oviedo.

\begin{abstract}
Pridolian to early Pragian shallow marine sediments in Celtiberia (Luesma Fm. and Nogueras Fm. and their equivalents) have a marked rhythmicity in lithologic phenomena and distribution of faunas (mainly brachiopods and conodonts are studied); some Pridolian to early Lochkovian pulses of clastic supply and immigration of faunas can be followed throughout Ibero-Armorica. This proves the continuity of the Westasturian-Leonese Basin with the middle and northern parts of the Armorican region. However, many marked sedimentary changes and limits of rhythmothems from mid-Lochkovian to initial Pragian are delimited to small structural areas and cannot be considered as correlative signals neither in a sequence analysis within Ibero-Armorica nor in a global eustatic event stratigraphy. The actual Pridolian-Pragian conodont "standard" zonation is insufficient as a sole means to establish an unambiguous T-R curve and to correlate it.
\end{abstract}

Keywords: Ibero-Armorica, Pridolian, Lochkovian, Pragian, rhythmothems, fluctuation of faunas, brachiopods, conodonts, critique of sequential correlation.

\section{RESUMEN}

Los sedimentos marinos someros del Pridoliense al Praguiense temprano de Celtiberia (Fm. Luesma y Fm. Nogueras y sus equivalentes) tienen una marcada ritmicidad tanto litológica como en la distribución de faunas (se estudian sobre todo braquiópodos y conodontos); algunos pulsos de aportes clásticos y de inmigración faunística se pueden trazar con cierto detalle a través de toda Ibero-Armórica. Esto muestra la continuidad paleogeográfica de la cuenca Asturoccidental-Leonesa con las partes medias y septentrionales de Armórica. Sin embargo, muchos cambios sedimentarios bien marcados y límites de ritmotemas se limitan a pequeñas áreas estructurales y no pueden utilizarse como indicadores para correlaciones ni en análisis sequenciales en IberoArmórica ni en estratigrafía de eventos eustáticos globales. La actual zonación estándar con conodontos del Pridoliense-Praguiense es insuficiente como único criterio para establecer y correlacionar una curva T-R segura.

Palabras clave: Ibero-Armórica, Pridoliense, Lochkoviense, Praguiense, ritmotemas, fluctuación de faunas, braquiópodos, conodontos, crítica de correlación secuencial.

\section{INTRODUCCIÓN}

Faunas del Devónico Inferior de Celtiberia han servido, en muchas ocasiones, como referencias para correlaciones suprarregionales atravesando los límites de biofacies. Dentro de Celtiberia, los datos bioestratigráficos forman una densa red. Pero en ella se combinan afloramientos que están separados hasta $150 \mathrm{~km}$ y que se sitúan a lo largo de ambos márgenes de la cuenca Asturoccidental-Leonesa. Como algunas formaciones afloran incompletas y como también hay tramos sin faunas útiles, dicha red tiene también algunas deficiencias. Pero como se solían destacar más las similitudes que las diferencias, los abundantes datos disponibles podrían sugerir que en Celtiberia existe una sucesión estratigráfica más o menos uniforme. La 
comprobada aplicabilidad, dentro y fuera de Celtiberia, de resultados relevantes podría subrayar esta impresión. Sin embargo, sólo existen determinados niveles con facies y faunas bastante uniformes en gran parte de la región (y en partes lejanas de Ibero-Armórica), mientras que otros intervalos difieren de área en área en un grado hasta ahora no suficientemente considerado. A pesar de estas diferencias, surge la pregunta de porqué se formaron tantos niveles y faunas casi uniformes en varias áreas de Celtiberia e Ibero-Armórica. A la vez, se examina críticamente el valor de cambios litológicos y bióticos para la estratigrafía secuencial en IberoArmórica y para la detección de verdaderos pulsos eustáticos.

Al comparar el Devónico Inferior de Ibero-Armórica con el del Renohercínico y otras áreas de Europa, destaca una particularidad ibero-armoricana: abundan tramos formados en aguas marinas someras, con límites bruscos, cuyas litologías y tipos de comunidades no se repiten. (En contraste, las lutitas y arenitas muy potentes del Renohercínico forman secuencias monótonas, sus faunas pueden persistir o reaparecer en grandes espesores, pero escasean los niveles-guía de extensión amplia.) Los cambios verticales en Ibero-Armórica demuestran una marcada ritmicidad, sobre todo en Celtiberia, y los niveles lateralmente uniformes en sendas áreas forman las bases de los ritmotemas intrarregionales (Carls, 1988). Sin embargo, bastantes ritmotemas con límites muy marcados dentro de un área no se extienden sobre toda Celtiberia (p. ej., el límite entre las Fms. Santa Cruz y Mariposas).

Algunas diferencias de facies y faunas entre Celtiberia y los equivalentes en León y Asturias se deben sin duda al hecho de que Celtiberia pertenecía a una cuenca más subsidente y las facies en León y Asturias se formaban sobre un zócalo menos subsidente. Esta es la razón principal por la cual hacemos sólo pocas referencias a las facies cantábricas. Dada la corta distancia, las diferencias climáticas no serían esenciales, pero aún así pudo haber diferentes temperaturas del mar: del Pridoliense hasta el Emsiense Inferior, muchos niveles en Celtiberia, sobre todo en su parte oriental, son ricos en cantos de fosfato (en el Guadarrama, los mayores espesores de silicatos diluían las concentraciones). Asimismo, faltan en Celtiberia estromatolitos y dolomías primarias, estromatopóridos y corales rugosos coloniales, y los tabulados y rugosos solitarios sólo tienen una representación modesta en algunos niveles. Como esto contrasta con algunos indicios de temperaturas más altas en León y Asturias, podría pensarse que las temperaturas del mar en Celtiberia eran algo más bajas debido a "upwelling" oceánico en las cercanías orientales, que suministraba también el fosfato. (El contenido en fosfato aumentó tambien durante la incursión de plancton y necton hercínico en el medio del Lochkoviense en el Guadarrama oriental, lo que indica una conexión con el mar abierto.)

La notable ritmicidad en las secuencias en Celtiberia podría invitar a buscar ciclos de Milankovitch en ella y a tratar de elaborar una estratigrafía secuencial a escala suprarregional. Pero se verá que muchos ritmotemas son sólo locales. Hasta que no se conozcan mejor muchos detalles, una estratigrafía secuencial sería demasiado especulativa. Sólo se proponen interpretaciones paleoecológicas de las faunas, basadas sobre todo en las supuestas capacidades de los filtradores para la extracción de su alimento de aguas turbias de arcilla y limo. En esta interpretación se sigue la distinción entre organismos turbidícolas, capaces de vivir con material en suspensión, y clarícolas, que no tienen suficiente defensa contra la turbidez y la carga indigerible de siliciclásticos (Carls et al., 1993). Esta distinción sustituye la atribución tradicional de fósiles del Devónico a la biofacies renana (aguas someras, oxigenadas) o a la biofacies hercínica (aguas profundas y pobres en oxígeno). La antigua clasificación se basaba más en la disponibilidad de oxígeno, sin considerar aspectos funcionales relacionados con la turbidez. Además, la asignación de turbidícola o clarícola considera también la transparencia del agua (algas, simbiontes algales de corales) y condiciones de visibilidad (trilobites, cefalópodos, peces) y de defensas contra el peligro de ser cubierto por sedimentos. En el Silúrico y en el Lochkoviense temprano de Celtiberia, la diferencia entre comunidades de braquiópodos turbidícolas o clarícolas aun no estaba bien marcada. Como lo nocivo para los clarícolas no es la fracción de tamaño arena gruesa, sino las fracciones más finas en suspensión, un substrato de arena bien lavada es apto para algunos clarícolas (p. ej., algunos rinconélidos). Esto es aplicable a la mayoría de las faunas de la Fm. Luesma y de sus equivalentes, porque a pesar de hallarse en sedimentos siliciclásticos de aguas someras, atribuidos tradicionalmente a la facies renana, sus braquiópodos podían filtrar igual que en la facies bohémica (aguas movidas, oxigenadas, pero sin arcilla y limo en suspensión). Es importante señalar que el grado de turbidez depende más de la frecuencia e intensidad del retrabajamiento de los sedimentos finos que de la cantidad de los aportes, de modo que la biofacies turbidícola, renana, no se correlaciona siempre con grandes espesores.

La cuenca paleozoica en Celtiberia era intracratónica y en ella dominaban sedimentos detríticos de ambientes neríticos someros. Por esto, las diferencias laterales se deberían sobre todo a aportes de distintas áreas fuente próximas a cada área de deposición. También las diferencias laterales en la ritmicidad se deberían a efectos locales de los aportes, de la subsidencia y de la exposición a corrientes y oleajes. Así, lo habitual serían las diferencias en las columnas estratigráficas, mientras que las interferencias de tendencias globales serían poco probables. Pero este modelo sencillo no explica el hecho de que las litofacies de cuarcita y sus faunas sean bastante uniformes en toda o casi toda Celtiberia y, en ciertos casos, hasta en regiones cantábricas y armoricanas, aunque su sedimento detrítico dependería mucho de las áreas fuente. Tampoco explica porqué la disminución de aportes terrígenos a mediados del Lochkoviense coincide con diferencias notables dentro de Celtiberia. Se necesita un modelo en el cual encajen tanto las diferencias locales como las uniformidades suprarregionales. 
Reevaluando conceptos anteriores, preguntamos: ¿Cuáles son los efectos y límites de los ritmotemas que sólo tienen validez local, y qué factores causaron los niveles de facies y faunas uniformes dentro de Celtiberia y en otras áreas de Ibero-Armórica? El resultado contribuirá, en el futuro, a distinguir los niveles potencialmente relevantes para una estratigrafía secuencial suprarregional de aquellos que sólo reflejan efectos locales, aunque espectaculares, irrelevantes fuera del área donde se observan.

\section{CONDICIONES REGIONALES}

En Celtiberia se conocen las siguientes áreas con secuencias de sedimentos y faunas bastante individualizados: 1) La depresión axial del río Cámaras (= DARC, comarca de Nogueras a Loscos en el anticlinal de Monforte de Moyuela y parte noroccidental del anticlinal de Montalbán, prov. Teruel; Carls, 1988). 2) La depresión axial de Nigüella, prov. Zaragoza (= NI; Valenzuela-Ríos, 1984, 1989). 3) El valle de la Cañadilla del Madronal, $4 \mathrm{~km}$ SSO de Henarejos, prov. Cuenca (= HEN; Carls, 1969; Viallard, 1973). 4) Terminación oriental del Guadarrama entre Cercadillo, Riba de Santiuste y Alcolea de las Peñas, prov. Guadalajara (= GU; Lotze, 1929; Carls, 1969; Bultynck y Soers, 1971).

Las dos áreas primeras pertenecen a la unidad estructural de Herrera de los Navarros, en la Cordillera Ibérica Oriental y corresponden al mismo cinturón de facies nerítica somera que se extiende a lo largo del margen suroccidental del Macizo Cantabro-Ebroico y cuyas facies detríticas estarían dominadas por aportes de dicho macizo.

HEN y GU estaban en el lado opuesto de la cuenca Asturoccidental-Leonesa, delante de la costa de un área ruente alargada, que posteriormente se convertiría en la zona estructural Galaico-Castellana (sensu Lotze, 1945). Esta área emergería ligeramente a partir del Silúrico final y se desarrolló desde el NO hacia el SE (Carls, 1983, 1988). En una posición análoga, referente a esta área, se hallaría el Devónico del Grupo de San Vitero en la región de Sanabria (Zamora; Aldaya et al., 1976).

El Devónico de la facies palentina de la Cordillera Cantábrica se ha interpretado como alóctono y procedente de partes más centrales de la cuenca Asturoccidental-Leonesa (Jahnke et al., 1983; Henn y Jahnke, 1984), lo que induce a buscar en él caracteres intermedios entre las facies de ambas zonas costeras en Celtiberia. Pero, salvo algunas correlaciones bioestratigráficas de las faunas $\mathrm{d} 1 \mathrm{~b} \beta 2, \mathrm{~d} 1 \mathrm{c} \alpha 2, \mathrm{~d} 1 \mathrm{c} \gamma$, d2a $\alpha 1$, MS6, límite d2c $\alpha / \beta$ (Carls, $1987 ; 1988$ ), no hallamos cambios sedimentarios y faunísticos idénticos como para incluir el Devónico palentino detalladamente en nuestro análisis.

La cuenca con los potentes sedimentos devónicos se continúa con facies similares, desde Celtiberia hasta el este del Macizo Armoricano. Sus márgenes más estables se situarían en el núcleo de la Rodilla Cantábrica y en el sur de Armórica. El conjunto es intracratónico. Los diversos e incongruentes escenarios de tectónica de placas, que proponen migraciones de microcontinentes y aperturas y cierres de varios océanos y oceanitos durante el Silúrico y Devónico en Europa (p. ej., Ziegler, 1988; Franke y Oncken, 1995), no influyen en la bioestratigrafía y paleozoogeografía aquí examinadas, ya que las áreas estudiadas pertenecen a la misma unidad cratónica.

\section{SIGNIFICADO DE LAS SIMILITUDES ESTRATIGRÁFICAS EN FACIES SOMERAS}

Similitudes estratigráficas significativas dentro de Ibero-Armórica y también en regiones adyacentes existen ya desde el Precámbrico final, pero se intensifican desde el Pridoliense. En cada uno de los cortes del Devónico de Celtiberia, se superponen, repetidas veces, facies neríticas bastante someras a facies de ambientes más abiertos y algo más profundos. Los tramos de facies someras presentan caracteres muy particulares, como niveles con cantos intraformacionales fosfatados, oolitos ferruginosos, ortocuarcitas muy blancas, calizas con laminación algal, bancos con faunas monoespecíficas, niveles con paleocanales y costras arcillo-ferruginosas in situ y retrabajadas. Sucesiones idénticas de algunos de estos fenómenos apoyan y refinan las correlaciones bioestratigráficas entre áreas separadas. Los tramos de facies hemipelágicas a pelágicas con sedimentos arcillosos oscuros (facies hercínica), suelen contener plancton de distribución suprarregional; siendo tan ubicuas, las lutitas pelágicas no sirven para distinciones paleogeográficas. Pero las coincidencias de facies someras son relevantes, ya que dependen esencialmente de los climas y suministros locales y difieren, por consiguiente, entre regiones sin relaciones estrechas.

En las páginas que siguen se describen en detalle las características litológicas, contenido faunístico y posición estratigráfica de los diez intervalos considerados en este trabajo (1-10). Además, se presentan algunas precisiones y revisiones taxonómicas correspondientes a los intervalos descritos. Asimismo, se realizan interpretaciones sedimentológicas, paleogeográficas, evolutivas y de correlación entre las áreas estudiadas, fundamentalmente GU, NI y DARC, pero también se hacen referencias a las secciones del Macizo Armoricano. Las características litológicas generales así como las correlaciones lito-, bioy cronoestratigráficas entre las tres áreas mencionadas (GU, NI, DARC) se presentan en la Fig. 1.

\section{1) Calizas en ampelitas del Pridoliense}

Hasta el Ludloviense, dominaban en Ibero-Armórica las ampelitas, en parte con graptolitos, que no permiten discernir relaciones regionales. En el Pridoliense temprano se formaron las primeras calizas. Aunque dentro de Celtiberia sólo se registran en el GU (Bultynck y Soers, 1971: 3; Bultynck, 1971), se repiten en la península de Crozon (Macizo Armoricano), en las 
localidades de Lostmarc'h (Bultynck y Pelhate, 1971) y de Porz ar Vouden (conodontos por Racheboeuf en Babin et al., 1979: 62-63, Lám. 2). En los tres casos se hallan, por encima de las pizarras ampelíticas, bancos delgados y/o concreciones de calizas con ortocerátidos y conodontos. Un poco por encima comienzan las cuarcitas finisilúricas de ambas regiones: Schistes de Lostmarc'h más Schistes et quarzites de Plougastel en Crozon y Fm. Alcolea en el GU. En Lostmarc'h, se cita Monograptus ultimus Perner como el graptolito más moderno debajo de las calizas; este graptolito limita la edad de los conodontos, hacia abajo, a una posición dentro del Pridoliense temprano. Las potentes unidades cuarcíticas, que siguen encima, ocupan el resto del Pridoliense. En todas las localidades se ha indicado la presencia de "Spathognathodus steinhornensis eosteinhornensis Walliser, 1964".

Aquí se tiene que explicar el significado taxonómico y estratigráfico del mecionado taxón de conodontos, porque en Armórica no se trata de Sp. st. eosteinhornensis sino de un nuevo taxón, y este hecho influye en la propuesta de correlación expuesta más abajo. Nos referimos a los siguientes ejemplares: Bultynck y Pelhate, 1971: Lám. 1, Fig. 2 (Figs. 1 y 3 peor conservados); Bultynck, 1971: Figs. 2.5-2.7; Racheboeuf en Babin et al., 1979: Lám. 2, Figs. 2, 4 y 1 (non "S. inclinatus").

La identificación original de estos y demás ejemplares, combinada con otros hallazgos en Bohemia, ha dado lugar a que se extienda el concepto de la Zona eosteinhornensis hasta un nivel demasiado antiguo (Bultynck y Pelhate, 1971: 191-194). Pero en los tres casos ibero-armoricanos no se trata del taxón "S. st. eosteinhornensis Walliser, 1964", sino de uno nuevo: "Ozarkodina (n. subg. W)" cuyas características son las siguientes: En el elemento Pa, fusión de dentículos centrales, nódulo(s) sobre lóbulo(s) lateral(es), cavidad basal amplia y situada posteriormente; elementos ramiformes con barras no onduladas de sección subcuadrada. Este indicador zonal no existe en el Pridoliense temprano, sino que empieza en el Pridoliense tardío.

Los conodontos ibero-armoricanos revisados aquí no corresponden a la diagnosis anterior y, por lo tanto, no indican la Zona eosteinhornensis. Los ejemplares iberoarmoricanos los clasificamos como Ozarkodina (n. subg. Z) n. sp. S que se caracteriza por presentar elementos ramiformes con barras onduladas; además los lóbulos laterales del elemento $\mathrm{Pa}$ no tienen nódulos. $\mathrm{La}$ distribución estratigráfica de ésta especie abarca desde el Pridoliense hasta el Lochkoviense temprano.

Las faunas de braquiópodos silúricos que tratamos a continuación se sitúan bastante por encima de Ozarkodina (n. subg. Z) n. sp. S, dentro del Pridoliense tardío, y podrían llegar a solaparse con la Zona eosteinhornensis s.s.

La formación momentánea de delgados niveles calcáreos con ortocerátidos y Ozarkodina n. sp. S, cerca del cambio de una sedimentación de ampelitas a fuertes aportes de arenas maduras dentro del Pridoliense temprano, sugiere una estrecha relación del GU con
Armórica en la misma cuenca. La ausencia de niveles calcáreos comparables en la Cordillera Ibérica Oriental se podría deber a transportes más intensos de arenas, ya desde el Ludloviense, que procedían del Macizo Cantabro-Ebroico y no permitirían la concentración de carbonatos (el paquete s3e $\gamma$ de la Fm. Bádenas con Monograptus fritschi linearis Boucek y las cuarcitas basales de la Fm. Luesma).

\section{2) Los braquiópodos de Porz ar Vouden (Pridoliense)}

Las formaciones con ortocuarcitas, que cruzan el límite Silúrico-Devónico en Ibero-Armórica, contienen varias faunas conchíferas de ambientes muy someros. Sólo la potente Fm. Alcolea, en el GU, contiene un mayor número de faunas pridolienses, mientras que en otras áreas ibero-armoricanas hay más niveles fosilíferos en el Lochkoviense. Como las fáunulas de los miembros Alc. 1 a Alc. 3 de la Fm. Alcolea no tienen equivalentes en las demás areas, no se tratan aquí.

Las faunas I y II en la parte inferior del miembro Alc.4 (Carls, 1977: 154, Fig. 5) contienen Leptostrophia voudenensis Mélou (= Leptostrophia sp. B sensu Carls, 1977) y Nucleospira sp. R. La fauna II está en un paquete de bancos muy gruesos de ortocuarcitas blancas. Ambos taxones se hallan también en la DARC, en las ortocuarcitas del miembro d1 1 i $\delta$ de la Fm. Luesma, donde se asocian con frecuentes Salopina missendenensis Straw y masas de una nueva especie de Plethorhyncha (Uncinulidae, Carls mscr.).

En Crozon, S. missendenensis, L. voudenensis y la nueva especie de Plethorhyncha (escasa, = "Rhynchonellida indéterminé" de Racheboeuf, en Babin et al., 1979: Lám. 7 Fig. 7) aparecen también, repentinamente, en un paquete cuarcítico, $13 \mathrm{~m}$ por encima de la base de la Fm. Plougastel (Babin et al., 1979), que es equivalente a las cuarcitas fosilíferas d $1 \mathrm{a} \delta$ de la DARC. Una diferencia interesante es que, en la Fm. Plougastel, el nicho ecológico de la nueva Plethorhyncha está ocupado por masas del rinconélido Clarkeia puilloni (Barrois) con afinidades malvinoafricanas (Babin et al., 1979: 77-79). La intrusión de este género en Armórica coincide, pues, con la breve instalación de un nivel extenso de abundante (aunque oligoespecífica) fauna conchífera en ambientes de alta energía. Inmediatamente después, desapareció la fauna conchífera, dejando el terreno a infauna de cuerpos blandos. Salvo la fauna III del GU, en pocos bancos areniscosos (unos $100 \mathrm{~m}$ debajo del límite S/D, Carls, 1977), y la fáunula d1b $\beta 1$ de la DARC, en un oolito ferruginoso, no se conocen faunas relevantes en Celtiberia hasta el tránsito al Devónico; estas faunas oligoespecíficas no tienen elementos comunes.

\section{3) Concentraciones ferruginosas cerca del límite Silúrico-Devónico}

Un poco por encima de las cuarcitas masivas del paquete $\mathrm{d} 1 \mathrm{~b} \alpha$ de la Fm. Luesma existe un oolito ferruginoso de $1 \mathrm{~m}$ de espesor que se extiende uniformemente en toda la DARC. Sin considerar unos lechos también muy ferruginosos inmediatamente debajo, 
este oolito es el nivel litológicamente más especial de la Fm. Luesma; contiene cantos blandos fosfatados, espinas de peces (?Acanthodii), "Camarotoechia" nucula (Sowerby) y bivalvos. Debido a su posición en la serie, casi $40 \mathrm{~m}$ por debajo de la primera fauna devónica, este nivel se situaría en el Pridoliense tardío, sin que su propia fáunula permita una datación directa.

En el GU, no se conoce una concentración comparable de hierro en el intervalo equivalente. Sin embargo, una acumulacion considerable se encuentra en la matriz de los bancos de arenisca roja que contienen la fauna $\mathrm{V}$ en medio del miembro Alc.4 de la Fm. Alcolea, que ya es Devónico basal. Estos dos eventos de fuerte acumulación de hierro en Celtiberia no coinciden. Mucho menos pueden correlacionarse los numerosos niveles ferruginosos de la Fm. Furada en Asturias con los de Celtiberia -no solo debido a la escasez de faunas. Evidentemente, los procesos que condujeron a la acumulación del hierro, restringiendo localmente los aportes de materiales siliciclásticos, no caracterizan niveles isócronos en toda Ibero-Armórica y no sirven para la estratigrafía secuencial a escala suprarregional. Esto no quiere decir que la frecuente formación de oolitos ferruginosos no sea un carácter común en Ibero-Armórica alrededor del límite S/D.

\section{4) EI tránsito Silúrico/Devónico (S/D)}

En el GU, la fauna IV de Carls (1977), que procede de los derrubios cuarcíticos de una alternancia areniscoso-pelítica de unos $50 \mathrm{~m}$ de espesor, está cerca del límite S/D y se sitúa un poco por debajo de la parte media del Mb. Alc.4 de la Fm. Alcolea (Carls, 1977; fig. 5). En esta mezcla de fauna hay elementos silúricos, como Shaleria sp. y una Salopina sp. de gran talla, que concurren con las últimas $L$. voudenensis; estos taxones faltan en la DARC, porque de sus capas limítrofes sólo las devónicas llevan fauna. Los primeros braquiópodos devónicos (o por lo menos mayoritariamente devónicos) que aparecen en el GU, sin que se sepa su orden cronológico exacto en los hallazgos sueltos, son el primer Terebratulida, Podolella rensselaeroides Kozlowski, y Platyorthis sp. D ex gr. monnieri (Rouault), que abundan también en la primera fauna devónica de la DARC. En las siguientes areniscas, muy ferruginosas, del GU, la diversidad de braquiópodos y bivalvos aumenta aún un poco en la fauna V de Carls (1977), que se sitúa aún en el Lochkoviense inicial (como no se conoce una asociación suficientemente similar en la DARC, la fauna V no se comenta aquí).

En la DARC, con menores espesores que en el GU, se concentran en unos pocos bancos en medio de una alternancia con cuarcitas claras (nivel d1b 32 de la Fm. Luesma) las entradas de las mencionadas Platyorthis y Podolella con Iridistrophia sp., Howellella del grupo $H$. mercurii (Gosselet), Alatiformia? sp. (sólo un ejemplar) y el trilobites Acastella heberti (Gosselet). Además, se encuentran "Camarotoechia" nucula, Homalonotinae, los bivalvos Actinopteria sp. y Grammysia sp., "Tentaculites" sp., ostrácodos lisos y crinoideos. Esta fauna es devónica, porque $A$. heberti solo se encuentra en la mitad inferior del rango de Monograptus uniformis Pribyl (Gandl, 1972).

Esta fauna conchífera, más diversa en la DARC desde el Ludloviense Inferior (unidad s $3 \mathrm{~d} \alpha$ de la Fm. Bádenas), se registra encima de unos $30 \mathrm{~m}$ de capas casi estériles, sin que tuviera lugar un cambio litológico notable. La entrada del grupo de $P$. monnieri caracteriza también el comienzo de la tradicional "Grès à Orthis monnieri" en Armórica, en la cual también aumentan las faunas en el límite S/D o poco después de él. Sin que cambiase el regimen de sedimentación de arenas maduras, se registran, pues, aumentos en la frecuencia de invasiones y en la diversidad de faunas conchíferas bentónicas en Ibero-Armórica desde el comienzo del Devónico, aunque la colonización de la cuenca sigue siendo discontinua hasta los finales de las formaciones cuarcíticas. Se ve, pues, que los cambios litológicos y la evolución de las faunas bentónicas no están siempre relacionados.

Un lentejón lumaquélico del nivel d1b $\beta 2$ en la DARC ha librado los conodontos devónicos más antiguos de Celtiberia, que no sólo apoyan la datación, sino también informan sobre la extensión geográfica de conodontos. Se trata de Icriodus wo. woschmidti Ziegler (Carls, 1975: Lám. 2, Figs. 19-20; non Fig. $21=$ I. woschmidti aff. woschmidti), I. woschmidti sspp. (diversas morfologías de plataformas), Delotaxis sp. (escasa) y una nueva especie del grupo $O$. remscheidensis: $O$. (n. subg. Z) remscheidensis n. ssp. z (= "Ozarkodina remscheidensis" de Carls, 1975: Lám. 2, Figs. 16-18).

$O$. (n. subg. Z) remscheidensis n. ssp. z aparece ya en el Pridoliense tardío de los Alpes Cárnicos en facies pelágica (tramo 40 del corte del Cellon de Walliser, 1964) y tiene una amplia distribución hasta la mitad del Lochkoviense inferior. Su primer registro en Celtiberia se retrasa hasta la parte media de su rango, porque no hay calizas anteriores que pudiesen contenerlo. Sin embargo, su hallazgo en la primera ocasión, a pesar de las condiciones del ambiente muy somero, indica la posibilidad de que este conodonto pudiera inmigrar libremente. La presencia de varios Icriodus muy tempranos demuestra igualmente que las aguas someras de Celtiberia pudieron ser invadidas sin retraso sensible después del origen de este género. (Como hallazgo más antiguo de Icriodus consideramos Icriodus n. sp. C de Uyeno, 1980, encima de Monograptus transgrediens Perner del Silúrico muy tardío y debajo de índices claros del Devónico en el norte de Canadá. En Europa faltan datos concluyentes sobre Icriodus en el Silúrico.) Por otro lado, las diversas morfologías de plataformas de Icriodus en el nivel d $1 \mathrm{~b} \beta 2$ representan una radiación endémica muy temprana, ya que no se han documentado formas comparables coetáneas en otras regiones. Esta radiación se debió probablemente a un aislamiento genético de poblaciones pequeñas -o sea a límites primero de panmixis y luego de emigración. Nos vemos, pues, ante un contraste entre las posibilidades de intercambio de las faunas de conodontos referente a la libre inmigración (por lo menos en algunos momentos) de especies cosmopolitas y las dificultades de los emigrantes de prosperar en otras regiones. La evolución particular, 
endémica, de la mayoría de los sucesivos taxones iberoarmoricanos de Icriodus (y Pelekysgnathus; ver Carls y Gandl, 1969; Carls, 1969, 1975; Valenzuela-Ríos, 1994) hasta el Praguiense temprano señala también que los conodontos originados en Ibero-Armórica no pudieron conquistar fácilmente otras regiones.

Hay que destacar que, tanto en el GU como en la DARC, la aparición de las faunas conchíferas devónicas se dio sin notable cambio de la litología. La formación de un lentejón de lumaquela, que ha librado los conodontos mencionados, no se debe considerar como un cambio, ya que sólo se trata de una momentánea concentración de conchas transportadas. Así, se presenta la invasión de los primeros taxones devónicos como un evento exclusivamente faunístico sin notable cambio ambiental impreso en el sedimento.

\section{5) El nivel con Baturria pini}

En la DARC, la base del miembro d1c de la Fm. Luesma consiste en unos $5 \mathrm{~m}$ de bancos gruesos de ortocuarcita blanca -una de las típicas bases de ritmotema de la Fm. Luesma. Con este pulso de la sedimentación, no aparece nueva fauna, pero un poco por encima de los bancos compactos aparece una fauna conchífera en pocos bancos de una alternancia arenoso-lutítica. Se trata de la Fauna d1c $\alpha 1$ con Howellella (Hysterohowellella) knetschi Carls y B. pini Carls. Esta fauna alcanza su mayor diversidad en la localidad Cabezo del Pino (Carls, 1974, 1985), donde se formó, sólo en una parte de su rango, un lentejón de oolitos ferruginosos con cantos blandos fosfatados; en otros afloramientos, el mismo nivel contiene menos taxones y puede carecer del hierro. Hay masas de Platyorthis sp. D ex gr. monnieri, abundantes B. pini, Dalejina frequens (Kozlowski), Mesodouvillina sp., Leptostrophia sp., Iridistrophia sp., "Camarotoechia nucula" (J. de C. Sowerby), Obturamentella? sp. 1, (= "Lanceomyonia cf. borealiformis" sensu Carls, 1977: 153), H. (H.) knetschi, Mutationella barroisi (Asselberghs), Actinopteria sp., Homalonotinae y la última Acastella heberti (Gosselet). Este nivel pertenece aún a la Zona de A. heberti y, por lo tanto, está dentro de la Zona de Monograptus uniformis (Gandl, 1972).

En el GU se hallan, $40 \mathrm{~m}$ por encima de la fauna $\mathrm{V}$, unos bancos de cuarcitas, que son más potentes y más blancas que la mayoría de las cuarcitas del Lochkoviense inicial en el GU. Este tramo correspondería a los bancos basales del miembro d1c en la DARC. Unos $6 \mathrm{~m}$ por encima se halla una fauna que comprende los taxones esenciales de la fauna d1c $\alpha 1$ : Platyorthis sp. D, B. pini, Mesodouvillina sp., "C. nucula", Obturamentella? sp. 1, H. mercurii (Gosselet), M. barroisi y una dudosa Hollardina sp. Excepto el último taxón (en la DARC,
Hollardina se conoce sólo en la fauna siguiente) y aunque en el GU falta un nivel de oolitos ferruginosos (pero muchos bancos arenosos son muy ricos en hierro), se da aquí una coincidencia significativa de un cambio litológico y la entrada de una fauna con unos taxones de rangos muy restringidos. Tanto en la DARC como en el GU, Obturamentella? y "Camarotoechia" son los taxones más clarícolas (los rinconélidos prefieren las aguas claras, y Hollardina probablemente también).

En la Rada de Brest desconocemos la fauna d1c $\alpha 1$, pero hay un nivel ferruginoso en una posición similar (debajo del equivalente de la fauna d1c $\alpha 2$, ver abajo). Elementos de la fauna existen en Armórica oriental (corte de Saint-Céneré, Carls, 1971); se hallan Platyorthis, Baturria, Dalejina y H. (H.) knetschi. Estos taxones facilitan la correlación, pero posiblemente no se concentran en solo un nivel como en Celtiberia. Aunque la coincidencia no es total y aunque la fauna no se ha documentado en todas las áreas ibero-armoricanas, se registra una colonización sincrónica y breve a lo largo de más de $1200 \mathrm{~km}$.

\section{6) El nivel con Fulcriphoria havliceki y Hollardina plana}

En la Fm. Luesma de la DARC y por encima de la fauna $\mathrm{d} 1 \mathrm{c} \alpha 1$, siguen menos de $5 \mathrm{~m}$ de alternancia, pero con más lutitas que antes. Luego hay unos $20 \mathrm{~m}$ de cuarcita en bancos gruesos con pocas lutitas. Aunque estas cuarcitas son masivas, grises e impuras, apenas se nota estratificación interna y sus fósiles están distribuidos caóticamente. Los bancos inferiores de este tramo contienen una fauna dominada por braquiópodos: Protocortezorthis sp., Platyorthis sp. E ex gr. monnieri (con valva dorsal algo convexa), Fulcriphoria havliceki Carls, Hollardina plana Racheboeuf y García-Alcalde, Mclearnitesella lecaroensis (Renouf), "Uncinulus" sp. (seno y burrelete con sólo unas 4 costillas y poco marcados), Meristella sp. G (abundante y hasta en masas), H. (H.) sp. ex gr. mercurii (escasa), ?Cyrtina sp. (un ejemplar incompleto), Grammysia sp. y Actinopteria sp. (escasas), colonias muy masivas de briozoos (abundantes).

Esta fauna es una mezcla de taxones turbidícolas o ambivalentes (Protocortezorthis, Platyorthis, Fulcriphoria, Mclearnitesella, Howellella y los bivalvos) y otros, que más bien se tienen que considerar como clarícolas porque sus familiares prosperaban generalmente en ambientes de aguas claras (Hollardina, "Uncinulus", Meristella, ?Cyrtina y los briozoos masivos).

En NI, el nivel d $1 \mathrm{c} \alpha 2$ se reconoce mediante el hallazgo de $H$. plana. Esta fauna no se ha encontrado en

Figura 1. Ensayo de correlación entre las columnas litoestratigráficas locales y unidades faunísticas de Guadarrama (GU), Nigüella (NI) y Depresión Axial del Río Cámaras (DARC).

1. Areniscas; 2. Calcarenitas o areniscas calcáreas; 3. Calizas; 4. Alternancia de lutitas y areniscas, predominan las lutitas; 5. Alternancia de areniscas y lutitas, predominan las areniscas. 6. Ortocuarcitas; 7. Margocalizas; 8. Margas; 9. Pizarras; 10. hierro; 11. nódulos de fosfato o fosforita; 12. lentejones o nódulos; 13. límite entre unidades lito o bioestratigráficas; 14. límite entre unidades cronoestratigráficas.

Punteado en el mapa de la Península Ibérica indica los afloramientos de materiales precámbricos y paleozoicos. 


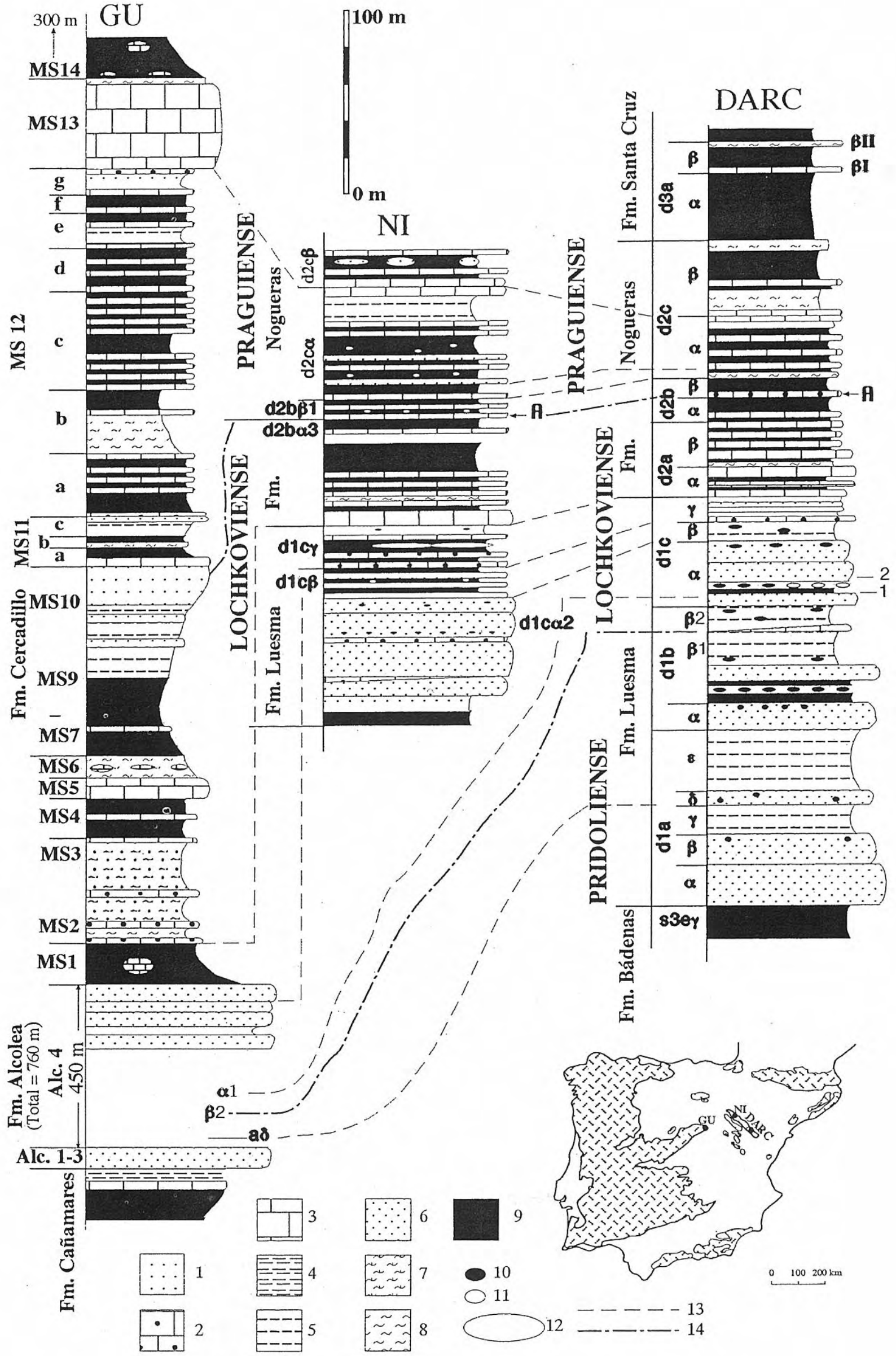


el GU; allí se halla solo Platyorthis sp. E, pero con distribución esporádica y mayor distribución vertical.

La mayoría de los braquiópodos se encuentran también en el Macizo Armoricano; por lo menos tres de ellos (H. plana, M. lecaroensis y $F$. havliceki) se concentran en areniscas impuras de la parte baja del Mb. Kerdéniel de la Fm. Landevennec (Rada de Brest). Un poco por debajo, hay un nivel ferruginoso, que podría corresponder, con cierto grado de inseguridad, al nivel oolítico del d $1 \mathrm{c} \alpha 1$ en la DARC (ver arriba). En Armórica, Meristella sp. G se halla reemplazada por $M$. renaudae Gourvennec y Racheboeuf -un caso de vicarianza similar al que concierne a la nueva especie de Plethorhyncha y Clarkeia puilloni en el Pridoliense (ver arriba).

Tanto en la DARC como en la Rada de Brest, por encima del nivel fosilífero con $H$. plana siguen unas decenas de metros de cuarcitas y alternancias de cuarcitas y pizarras con poca fauna; en el GU, la situación es similar. De este modo, el corto intervalo con $H$. plana y $F$. havliceki destaca como otro episodio de invasión de una nueva fauna particular, en la cual faltan los elementos esenciales de la fauna anterior. En este caso, las condiciones litológicas mencionadas referente a la DARC y aludidas para la Rada de Brest insinúan que existe una relación de la invasión con un cambio en el ambiente, pero aun no podemos interpretarla.

Recordemos aquí que durante el Pridoliense y Lochkoviense inferior temprano hubo coincidencias significativas entre pulsos bruscos de la sedimentación de cuarcitas y entradas repentinas de faunas particulares, que afectaron simultáneamente a grandes partes de IberoArmórica. En los intervalos que siguen hasta el Lochkoviense final, este paralelismo y la ritmicidad de la acumulación disminuyen notablemente, mientras que las comunidades de faunas conchíferas adquieren una estabilidad, cada una en su región, más duradera a pesar de mayores diferencias laterales.

\section{7) El cese de aportes arenosos y los inicios de la colonización permanente de la cuenca}

Las formaciones areniscosas en Ibero-Armórica, que comienzan en el Pridoliense, terminan cerca del medio del Lochkoviense. Como los aportes arenosos cesaron en un intervalo corto, se interpretaba como un fenómeno isócrono, pero el cambio fue diacrónico y no se trata de un "evento" relevante para la estratigrafía secuencial. De modo general, en los tramos superiores de las cuarcitas se intercalan areniscas muy fosilíferas o calizas lumaquélicas y después se forman alternancias de lutitas y calizas.

En la Fm. Luesma de la DARC, despues de unos $30 \mathrm{~m}$ de cuarcitas y alternancias prácticamente estériles encima de la fauna $\mathrm{d} 1 \mathrm{c} \alpha 2$, ya aparecen esporádicamente, en algunos bancos del paquete d1c $\beta$, Platyorthis, "Tentaculites", Grammysia, Nuculites y ortocerátidos. Esta entrada de una nueva fauna conchífera coincide con un aumento en cantos de fosfato. Bancos ricos en fosfato suelen contener abundantes restos de peces, sobre todo en la Fm. Nogueras de la DARC y de NI.

En el paquete d1c $\gamma(13 \mathrm{~m})$ de la Fm. Luesma en la DARC, los contenidos mencionados aumentan de repente y se intercalan lentejones y bancos de lumaquelas entre los bancos arenosos. Así se inicia el tránsito de arenas de cuarzo maduras de la Fm. Luesma a las calizas bioclásticas de la Fm. Nogueras. Las lumaquelas del paquete $\mathrm{d} 1 \mathrm{c} \gamma$ contienen: Platyorthis sp., Proschizophoria falsa interpres Carls, Schizophoria runegatensis Renouf, M. lecaroensis, Geniculomclearnites levicaudata GarcíaAlcalde, Boucotstrophia? sp., Iridistrophia sp., "Uncinulus" sp., Protathyris sp., pequeños "Anathyris" ex gr. undata (Defrance), H. (H.) cortazari Carls. Además hay Orbiculoidea sp., lingúlidos, Actinopteria sp., Nuculites sp., "Tentaculites" sp., Homalonotinae, Acastella spp., ostrácodos (Ulrichia, Cytherellina), briozoos ramiformes, incrustantes y masivos (Cyclostomata, abundantes) y Aulopora sp. Abundan microfósiles, como conodontos, restos de conularios y de filocáridos y, sobre todo microictiolitos (Mader, 1986; Wang, 1993). El solapamiento de Acastella cf. heberti elsana (Rud. y E. Richter) y A. tiro (Rud. y E. Richter) indica el comienzo de la Zona tiro en la parte baja del paquete (Gandl, 1972).

Los conodontos, como los invertebrados, no evolucionaron notablemente en el paquete $\mathrm{d} 1 \mathrm{c} \gamma$, lo que sugiere que éste se formó en poco tiempo. Se trata de 8 taxones: una forma tardía de Ozarkodina $r$. remscheidensis (Ziegler), O. r. repetitor (Carls y Gandl); un ejemplar de "O." carlsi (Boersma), Icriodus woschmidti transiens Carls y Gandl, I. angustoides bidentatus Carls y Gandl $I$. $r$. rectangularis Carls y Gandl, Pelekysgnathus serratus elongatus Carls y Gandl y $P$. s. elatus Carls y Gandl. En la DARC, estos conodontos se obtienen por primera vez, localmente, de paleocanales de calcarenita gruesa en la base del paquete, al ser éstos los primeros materiales solubles; pero en la Fm. Luesma de NI, $I$. a. cf. bidentatus aparece ya en un lentejón de lumaquela con índices de la fauna d1c $\alpha 2$, lo que muestra que los orígenes de los taxones mencionados pueden ser algo anteriores a sus primeros registros logrados en la DARC.

En este punto, necesitamos hacer algunas rectificaciones referentes a la biozonación convencional de conodontos. Los conodontos mencionados anteriormente, sobre todo $I$. $w$. transiens, que erróneamente se ha sinonimizado con $I$. $w$. postwoschmidti Mashkova, han servido de referencia principal para la Zona postwoschmidti; este formalismo ha generado bastante confusión. Una zona denominada postwoschmidti empezaría, según los datos resumidos por Nikiforova, 1977: Fig. 4, ya en el medio del rango de Acastella heberti, o sea entre las faunas $\mathrm{d} 1 \mathrm{~b} \beta 2$ y $\mathrm{d} 1 \mathrm{c} \alpha 1$ de la Fm. Luesma; pero I. w. postwoschmidti es, a su vez, tan endémico como algunas especies de Icriodus de Celtiberia.

Estos conodontos son mayoritariamente endémicos como también los Icriodus de la fauna d $1 \mathrm{~b} \beta 2$. La presencia de $I$. $w$. transiens, I. a. bidentatus y (algo retrasado) P. s. elongatus también en el Pirineo Central, 
pero no en áreas pelágicas más lejanas, subraya la restricción de esta asociación a Ibero-Armórica y sus cercanías.

"O." carlsi es el taxón del d1c $\gamma$ que tiene mayor distribución geográfica y se encuentra preferentemente en ambientes pelágicos (Pirineo Central; Frankenwald; Bohemia); las dos subespecies mencionadas de $O$. remscheidensis se conocen también en la región ardenorenana, pero no son cosmopolitas. (El taxón $O$. remscheidensis Ziegler empieza dentro de la Zona de $A$. heberti y termina temprano dentro de la Zona de A. tiro, y la mayoría de sus citas a escala global desde el comienzo del Devónico son erróneas.) El endemismo de algunos Icriodus de Celtiberia está bien expresado por la vicarianza de $I$. $w$. transiens e $I$. a. bidentatus en Celtiberia, frente a $I$. $w$. postwoschmidti e $I$. eolatericrescens Mashkova en Podolia. Aunque estos pares de taxones han sido sinonimizados, son diferentes. Aún no podemos interpretar estos datos paleozoogeográficamente, pero si incluso los conodontos se hallan involucrados en endemismo, es que debió de existir una situación particular.

Encima del nivel faunístico d1c $\alpha 2$ en NI, siguen unos $30 \mathrm{~m}$ de ortocuarcitas masivas, que atribuimos aún al paquete $\mathrm{d} 1 \mathrm{c} \alpha$, y unos $10 \mathrm{~m}$ de alternancia arenosa con fosfato, que puede corresponder al paquete $\mathrm{d} 1 \mathrm{c} \beta$ en la DARC. Las siguientes areniscas calcáreas $(2 \mathrm{~m})$ recuerdan el paso $\mathrm{d} 1 \mathrm{c} \beta / \mathrm{d} 1 \mathrm{c} \gamma$ en la DARC, pero mientras que en la DARC se establece enseguida una fauna rica y diversa, ésta escasea en los $16 \mathrm{~m}$ siguientes (dos tramos de lutitas de $5 \mathrm{~m}$ y $6 \mathrm{~m}$ separados por $5 \mathrm{~m}$ de calcarenitas). Los $12 \mathrm{~m}$ finales de la Fm. Luesma en NI, una alternancia de areniscas y calizas con lutitas, con $I$. rectangularis $\mathrm{ssp}$. en la base, contienen más fósiles y se comparan también litológicamente con el paquete d1c $\gamma$ de la DARC, a cuya parte alta corresponderían. En NI, el espesor total (unos $28 \mathrm{~m}$ ) del probable equivalente del $\mathrm{d} 1 \mathrm{c} \gamma$ es más del doble que en la DARC (unos $13 \mathrm{~m}$ ); a esta diferencia puede contribuir que lutitas tan potentes como en NI faltan en la DARC.

Las lutitas son también importantes en el GU. 15 m por debajo del techo de la Fm. Alcolea y aún en bancos gruesos de areniscas cuarcíticas, aparecen escasos Acastella sp., P. ex gr. monnieri y una forma primitiva de Howellella (Hysterohowellella) cortazari (Carls et al., 1993: Fig. 2, Lám. 1, Figs. 1-13), que puede ser un poco anterior a las poblaciones del área típica. Por lo tanto, el final de las cuarcitas Alc.4 en el GU, donde la fauna vuelve a ser muy escasa, sería de edad similar al comienzo del paquete $\mathrm{d} 1 \mathrm{c} \gamma$ en la DARC con su rica fauna. En la base de la Fm. Cercadillo, la unidad MS1 (Sommer, 1965; revisada por Carls, 1969, 1987: Fig. 8) consiste de unos $20 \mathrm{~m}$ de lutitas algo limosas y margosas sin fauna relevante. Como los conodontos del banco basal de la unidad MS2 corresponden al límite entre las Fms. Luesma y Nogueras, el tramo MS1 lutítico del GU equivale a gran parte del d1c $\gamma$ aún arenoso en la DARC.

Según Morzadec y Paris (1976: 13), en el este de Armórica las arenas se acabaron algo después de la extinción de A. tiro.
Estas comparaciones sugieren que la entrada y permanencia de fauna algo abundante en NI y GU son posteriores a la eficaz colonización en la DARC. De ser así, lo que favoreció a la fauna no fue la disminución de los aportes arenosos, sino que la nueva fauna se instalase primero en el área donde se mantuvo el suministro de arena. Entre las nuevas faunas, que son más diversas y mucho más longevas que las del Pridoliense y Lochkoviense más temprano, hay diferencias notables. Resulta pues, que no existe una simple relación causal entre aportes terrígenos y colonización y que los cambios en la sedimentación no coinciden con cambios ecológicos. Faltan, pues, señales válidas para una estratigrafía secuencial suprarregional. Que el cambio tan radical arena/caliza fuera un proceso diacrónico con particularidades locales, no le resta valor en la geología histórica de Ibero-Armórica.

\section{8) EI Miembro d2a de la Fm. Nogueras y parte de sus equivalentes}

El cambio de un régimen de arenas a uno de carbonatos en toda Ibero-Armórica no se puede interpretar como consecuencia de una tendencia eustática transgresiva, porque fue diacrónico. Se relaciona mejor con una disminución de los relieves en las áreas-fuente, aunque este aspecto tampoco sería suficiente por no ser el único relevante. A pesar de la tendencia común en toda Ibero-Armórica, la sedimentación y las comunidades de fauna conchífera varían de un área a otra: la relativa uniformidad horizontal de las cuarcitas y de sus faunas sucesivas es ahora relevada por una diversidad mayor de lito y biofacies simultáneas. Vamos a resaltar las particularidades de las distintas áreas en Celtiberia.

La Fm. Nogueras en la DARC y en NI es una alternancia de bancos de calizas impuras mayormente lumaquélicas con lutitas más o menos limosas. Hay pocos bancos arenosos. Abundan los braquiópodos, y muchos bancos llevan cantos de fosfato. En la DARC el mb. d2a mide $40 \mathrm{~m}$, en NI algo más. Su tasa media de acumulación se estima en poco más de $25 \mathrm{~m} / \mathrm{ma}$; el paquete $\mathrm{d} 2 \mathrm{a} \alpha(16 \mathrm{~m})$ representa la mayor parte del tiempo. La biofacies del mb. d2a es fundamentalmente turbidícola, renana, y solo a veces aparecen pocos taxones clarícolas, sin que la profundidad, que siempre oscilaba en el submareal muy somero, aumentase notablemente.

En los primeros bancos de la Fm. Nogueras, los siguientes conodontos son nuevos: I. rectangularis lotzei Carls, I. vinearum Carls e I. fallax fallax Carls. A la vez, faltan los indicadores de la parte baja del paquete d1c $\gamma$ (de la parte alta no hay registro). 1,5 m encima de la última cuarcita en la DARC, se halla un nivel decimétrico de oolitos ferruginosos. Tanto la concentración de los cambios en los linajes de Icriodus en tan poco espesor como la concentración de hierro sugieren una cierta condensación en la DARC. (Concentraciones de hierro hay también en el paso de cuarcitas a calizas en la Rada de Brest, sin que sus edades tengan que ser idénticas.)

Las faunas del miembro d2a de la Fm. Nogueras en la DARC y en NI son muy parecidas; hasta ahora, solo hay 
documentación detallada en la DARC. Dominan: Platyorthis spp. (línea evolutiva), Proschizophoria falsa sspp., Schizophoria sp., Mclearnitesella sp., Iridistrophia sp., un nuevo género (="Stegerhynchus", de anteriores trabajos), "Anathyris" ex gr. undata (linea evolutiva), $H$. (H.) cortazari (paquete $\mathrm{d} 2 \mathrm{a} \alpha$ ), seguida por $H$. (H.) lunae Gourvennec (d2a $\beta)$, Mutationella ex gr. barroisi, Cryptonella? spp. (linaje con aumento de talla). Sin tener en cuenta sus estadios evolutivos, estos braquiópodos forman una asociación bastante permanente, cuyas raíces están ya en la fauna d1cy. Frecuentes Actinopteria spp., tentaculítidos, gasterópodos (Platyceras en calizas encriníticas, Bucanella), Parahomalonotus, Acastella spp. y restos de crinoideos y de asterozoos completan las asociaciones con alguna variación.

La ritmicidad litológica no es notable y las fluctuaciones faunísticas son ligeras, transitorias y breves. Chaetétidos, el tabulado Aulopora, y los braquiópodos Dichozygopleura y Guaxa, Uncinulus y otros rinconélidos comunes en otras regiones con aguas claras, se hallan sólo en algunos bancos en medio del mb. d2a; a la vez, abunda I. f. fallax, que es el vicariante endémico del cosmopolita Pedavis de aguas más abiertas. Una diversidad mayor en bivalvos (Nuculites spp., Palaeoneilo, Leiopteria, Palaeopecten, Modiolopsis) se halla, junto con Acastella, Homalonotinae y ostrácodos, en las lutitas d2a $\alpha 4$ (final de A. tiro), donde los braquiópodos son algo menos diversos. Restos de peces y de filocáridos comienzan a abundar en medio del paquete d2a $\beta$, solapándose aún con los últimos Uncinulus. En la unidad d2aß5, céspedes de Cryptonella o de Iridistrophia fueron enterrados por tempestitas. En la base de esta unidad, asociados al césped de Cryptonella, se hallan los primeros placodermos, que son de talla media. Más frecuentes son "bonebeds" de escamas y espinas de Acantódidos y dientes del elasmobranquio Leonodus, que abundan también en los últimos dos bancos del mb. d2a, donde dominan bivalvos (Nuculites, Leiopteria, Modiolopsis, Grammysia, Goniophora) y escasean los braquiópodos. Directamente encima (unidad d2b $\alpha 1$ ), hay restos de esta asociación en paleocanales. Parece ser que la riqueza en peces y la sustitución de los braquiópodos por bivalvos están relacionadas con una somerización, a veces extrema.

En el GU, el comienzo del equivalente del mb. d2a se reconoce mediante la fauna de conodontos GU1 (unidad MS2), que contiene formas transicionales de $I . r$. rectangularis a $I$. r. lotzei y de $I$. a. bidentatus a $I$. $a$. alcoleae. Estos indican una edad inmediatamente posterior a la del final de la Fm. Luesma y, aunque las litologías son diferentes, se correlacionan con el comienzo de la Fm. Nogueras. En el GU, siguen lutitas margosas con laminación de abundantes limos y algunos bancos calcáreos y de areniscas finas con estratificación oblicua; la potencia de estas rocas es ligeramente superior a $50 \mathrm{~m}$ y terminan con unos bancos lumaquélicos ricos en $H$. (H.) cortazari, que libraron la fauna de conodontos GU10 de Carls (1969: Fig. 2, Tab. 1; Carls 1987: Fig. 8). Los $50 \mathrm{~m}$ comprenden las unidades MS2 y MS3, definidas vagamente por Sommer (1965) y partes de la unidad Ce1a de Bultynck y Soers (1971). Se trata del final de los transportes (desde el Pridoliense) a lo largo de la Zona Galaico-Castellana (Carls, 1983, 1988). En el GU, la cuenca subsidía aún bastante, mientras que en la DARC y en NI los aportes (¿del Macizo CantabroEbroico?) y la subsidencia ya casi habían cesado: los equivalentes, en la DARC, parecen ser unos $6 \mathrm{~m}$ de calizas biogénicas con pocas lutitas.

En el GU, el siguiente tramo de unos $40 \mathrm{~m}$ consta de las unidades MS4 (20 m de lutitas con canales y bancos de caliza), MS5 (11 m de alternancia de calizas y lutitas) y MS6 (10 m de lutitas con bancos y nódulos de margas), y se compara con las unidades d2ao2(?)-6 de 10 a $12 \mathrm{~m}$ de espesor.

En el GU, la fauna es abundante en este tramo, aunque menos que en la DARC. De los braquiópodos dominantes del mb. d2a en la DARC, sólo unos pocos elementos se hallan en el GU con frecuencia: Mesodouvillina y/o Mclearnitesella, $H$. $(H$.) cortazari; a estos se les asocian, con mayor frecuencia que en la DARC, "Tentaculites", Acastella (y Protacanthina) y Homalonotinae. Los trilobites son más frecuentes, pero la mayoría de la fauna conchífera aragonesa falta, y las escamas de peces escasean. Por otro lado, en el GU hay más rinconélidos ("Lanceomyonia") y Meristella y el tabulado Parastriatopora abundan en las margas indicando aguas claras. Cefalópodos ortocónicos, bivalvos epiplanctónicos (Panenka) y nowakiidos (solo en ciertos bancos) son elementos de la facies hercínica.

Hasta en las faunas de conodontos existen marcadas diferencias. En el GU, I. a. angustoides e I. f. fallax faltan en el Lochkoviense y de $I$. vinearum solo se hallaron dos ejemplares aberrantes, mientras que $I$. rectangularis lotzei, I. a. alcoleae, Pelekysgnathus spp. y Ozarkodina (n. subg. Z) $r$. repetitor existen en ambos lados de la cuenca. Por otra parte, se encuentra sólo en el GU todo el linaje desde Ancyrodelloides transitans (Bischoff y Sannemann) hasta A. kutscheri Bischoff y Sannemann, acompañado por $O$. wurmi (Bischoff y Sannemann) y seguido por Pedavis robertoi Valenzuela-Ríos y $P$. gilberti Valenzuela-Ríos. Estos conodontos cosmopolitas son taxones de mares abiertos y elementos de la facies hercínica. Igual que los otros elementos hercínicos mencionados, encontraron acceso al GU porque en este intervalo la subsidencia era aquí algo mayor que la acumulación causándose una profundización de dos o tres docenas de metros. Las diferencias de las faunas y de las litofacies resultantes son tantas, que se parecen muy poco a la uniformidad que reinaba en las formaciones de cuarcitas precedentes. Al no hallarse una tendencia paralela en la DARC, la profundización no se debe a un pulso eustático.

La profundización, tal y como la indican los taxones hercínicos, se data como sigue: hacia el techo de las lutitas MS4 se halla Homoctenowakia cf. senex (Alberti), que estaría en la parte más baja de la Zona de Monograptus hercynicus. En las calizas que siguen (MS5 bajo), aparece A. trigonicus Bischoff y Sannemann, que indica la Zona trigonicus-pandora $\beta$ (Valenzuela-Ríos y Murphy, 1997), y Acastella tiro. La última, al extinguirse 
poco después, se correlaciona con las lutitas d2a $\alpha 4$ en la DARC, donde una fauna con abundantes ostrácodos y bivalvos intercalada en lutitas estériles indica una somerización pasajera, que contrasta con la profundización en el GU. Este contraste indica que la profundización no se debe a efectos eústaticos. En la fase terminal de la profundización se halla Homoctenowakia cf. bohemica (Boucek), y P. gilberti indica la Zona gilberti-eosulcatus, ya dentro del Lochkoviense superior. En este nivel aún no aparecen indicadores del paquete $\mathrm{d} 2 \mathrm{a} \beta$ de la DARC, que por lo tanto equivale a alguna parte baja del tramo estéril que sigue en el GU.

\section{9) El tramo granocreciente MS7 a MS10 en el GU y sus equivalentes}

Encima de la unidad MS6 en el GU con sus elementos hercínicos, acaba la producción de caliza fosilífera y se depositan lutitas, primero algo margosas y pronto limosas y sin fauna que gradan a una alternancia de areniscas y lutitas, que termina con bancos fuertes de arenisca. Se trata de las unidades MS7-10 de Sommer (1965) y Ce2 de Bultynck y Soers (1971), que, revisadas, suman poco más de $100 \mathrm{~m}$. Constituyen la parte granocreciente y somera de un ritmotema típico de Celtiberia (Carls 1988), sin oscilaciones notables en su interior. (El comienzo de este ritmotema estaría debajo del intervalo con elementos hercínicos, MS5-6, sin que se pueda definir estrictamente, debido a las fluctuaciones ligeras en el intervalo MS1-4.) Un poco por debajo de su techo, Acastella cf. rouaulti (Tromelin y Lebesconte), un taxón poblemático, indicaría el Lochkoviense tardío, mientras que el estado evolutivo de un espiriférido ya sugiere el Praguiense (Carls et al., 1993: 253). Sólo $12 \mathrm{~m}$ por encima, se halla Vandercammenina ovetensium Carls, que desciende de $V$. sollei Carls, la cual aparece en el comienzo del Praguiense en la DARC. Esta relación sugiere que la alternancia arenosa MS10 termina en el Praguiense muy temprano. Por consiguiente, los más de $100 \mathrm{~m}$ de alternancia granocreciente en el GU equivalen, en la DARC, a los paquetes $\mathrm{d} 2 \mathrm{a} \beta, \mathrm{d} 2 \mathrm{~b} \alpha$ y a la parte basal del paquete $\mathrm{d} 2 \mathrm{~b} \beta$ de la Fm. Nogueras, que suman menos de $40 \mathrm{~m}$ de espesor (la mayoría del Lochkoviense tardío y muy poco del Praguiense inicial). Sus equivalentes en la DARC no son tan claramente granocrecientes, sino que se reconocen allí por varias fluctuaciones de facies en ritmotemas menores.

El paquete $\mathrm{d} 2 \mathrm{a} \beta$ en la DARC ya se ha caracterizado antes; su parte alta corresponde con una somerización primera. La unidad $\mathrm{d} 2 \mathrm{~b} \alpha 1$ (unos $4 \mathrm{~m}$ de lutitas y paleocanales arenosos) es de facies bastante somera y constituye el segundo ritmotema, que es incompleto. La siguiente unidad, d2b $\alpha 2$, con hasta $5 \mathrm{~m}$ de bancos gruesos de calizas lumaquélicas e intercalaciones lutíticas, representa el tercer ritmotema; comienza con un nivel oolítico ferruginoso en la base, que indica una condensación y pasa a poblaciones in situ de Cryptonella y asociaciones oligoespecíficas de los braquuiópodos del paquete $\mathrm{d} 2 \mathrm{a} \beta$, excepto los primeros Hysterolites gandli Carls. Las calizas terminan en un banco encrinítico con abundantes ejemplares de Schizophoria n. sp. w y uncinúlidos; éste último banco corresponde a una fase corta de aguas limpias, que es el comienzo del cuarto ritmotema cuyo tramo granocreciente arcilloso-arenoso constituye la unidad $\mathrm{d} 2 \mathrm{~b} \alpha 3$, de unos $8 \mathrm{~m}$. En la parte baja de éste se halló un "arrecife" de briozoos y tabulados de $20 \mathrm{~cm}$ de diámetro como única construcción "biohermal" del Lochkoviense en la DARC. El ritmotema termina en la base del banco A con $V$. sollei, o sea en el comienzo del Praguiense. Un quinto ritmotema (= unidad d2b $\beta 1,8$ $\mathrm{m})$, predominantemente lutítico, comienza en el banco A. El banco A se extiende uniformemente sobre toda la DARC y tiene, en su mitad superior, una rica fauna que incluye, entre otros, Schizophoria n. sp. b. El rinconélido Trigonirhynchiidae, Vandercammenina y los briozoos fenestélidos son formas clarícolas de este banco (para los restantes taxones: véase Carls, 1987: 117). En el resto de este ritmotema, que es de facies somera, la fauna escasea. La presencia de $I$. a castilianus Carls, en las calizas basales de un sexto ritmotema (unidad d $2 \mathrm{~b} \beta 2,2 \mathrm{~m}$ ), permite correlacionarlas con la mitad superior de la unidad MS12a en el GU. Por lo tanto, es de suponer que el techo de la unidad MS10 y la unidad MS11 del GU tienen sus equivalentes en la DARC, dentro del ritmotema $\mathrm{d} 2 \mathrm{~b} \beta 1$, sin que se puedan delimitar en detalle.

En NI se hallan $V$. sollei, Schizophoria n. sp. b y otros taxones del banco A de la DARC, en una costra ferruginosa con fosfato, que cubre un banco grueso (60 $\mathrm{cm}$ ) de caliza con briozoos. Los $8 \mathrm{~m}$ de lutitas debajo de la caliza se comparan con la unidad d2b $\alpha 3$ de la DARC, y los $4 \mathrm{~m}$ de lutitas encima de la costra se comparan con la unidad $\mathrm{d} 2 \mathrm{~b} \beta 1$; ambos tramos son ligeramente granocrecientes y corresponden a ritmotemas como en la DARC. También el siguiente ritmotema (unidad d $2 b \beta 2,2$ m) de la DARC se deja identificar en los cuatro bancos de caliza $(1 \mathrm{~m})$ y las siguientes lutitas $(1 \mathrm{~m})$ con paleocanales arenosos en NI. Por lo tanto, hay un paralelismo notable entre DARC y NI en estos intervalos. La entrada de $I$. a castilianus en la base de la unidad $\mathrm{d} 2 \mathrm{~b} \beta 2$, indica que esta unidad ya equivale a las calizas del medio (aun no en la base) de la unidad MS12a en el GU.

Tanto en la DARC como en NI, los siguientes cambios sedimentarios (límites de ritmotemas) y faunas existentes en el GU no se hallan expresados: el comienzo de un ritmotema con unos bancos carbonatados en la base de la unidad MS11a; $1 \mathrm{~m}$ de margas con la fauna de $V$. ovetensium, que forman la base del ritmotema MS11b; una fauna turbidícola, dominada por Hysterolites gandli en las lutitas, $1 \mathrm{~m}$ por encima de la última. Pocos metros de alternancia granocreciente de lutitas y areniscas con otra fauna turbidícola hacia el techo de la unidad MS11c, podrían coincidir con el fin del ritmotema $d 2 b \beta 1$, sin embargo, todavía no se dispone de evidencias paleontológicas.

Resumiendo, los ritmotemas cerca del límite Lochkoviense/Praguiense, aunque sean de estructuras bastante similares, no coinciden entre el GU y el margen nororiental de la cuenca, mientras que, a lo largo de este margen, se registran pulsos sincrónicos y secuencias similares (aunque con diferentes espesores). La 
ritmicidad se debe, por consiguiente, a subsidencia y suministros y no a tendencias T-R eustáticas. El supuesto evento global de un pulso regresivo en el comienzo del Praguiense no se puede identificar en Celtiberia.

Chonetes pinguis Racheboeuf, en la unidad $\mathrm{d} 2 \mathrm{~b} \beta 2$ de la DARC es el primer chonétido devónico que alcanza Celtiberia en el curso de la expansión de los chonétidos desde Armórica (ver Racheboeuf, 1981: 253-268. Los chonétidos presentan varios ejemplos de entradas muy heterocrónicas en las diferentes partes de IberoArmórica).

\section{0) El sincronismo celtibérico en el mb. d2c de la Fm. Nogueras y sus equivalentes}

El comienzo del paquete d2c $\alpha$ en la DARC y en NI, lo marca una fauna casi monoespecífica de Platyorthis ex gr. circularis (Sowerby). De aquí en adelante, hay sucesiones similares de faunas y litologías en la DARC y en NI. Las calizas basales de las unidades se identifican en ambos lugares mediante los siguientes caracteres: d2c $\alpha 1$ : P. ex gr. circularis; d $2 \mathrm{c} \alpha 2$ : entrada de Mauispirifer sp. H Carls y Heddebaut (en la DARC hay, además, Plebejochonetes oehlerti (Racheboeuf), restos de peces y cantos de fosfato); d $2 \mathrm{c} \alpha 3$ : entrada de una Fascistropheodonta de tamaño mediano y de grandes Mauispirifer. Incluyendo los bancos basales de la unidad $\mathrm{d} 2 \mathrm{c} \alpha 3$, se miden en la DARC $6 \mathrm{~m}$ y en NI $4 \mathrm{~m}$ (en el resto del paquete $\mathrm{d} 2 \mathrm{c} \alpha$, los espesores en NI miden algo más del triple que en la DARC). Los equivalentes en el GU son partes altas de la unidad MS12a y la unidad MS12b, unos $60 \mathrm{~m}$ de alternancias primero de calizas y luego de margas de braquiópodos con lutitas, que forman la parte final del tramo Lochkoviense-Praguiense y son claramente diferentes del conjunto de DARC y NI.

Desde la unidad MS12c en adelante, la sucesión en el GU vuelve a presentar detalles de facies en un orden comparable a la sucesión en la DARC y en NI. En DARC, NI y GU, se encuentran repetidas veces niveles de calizas margosas y algo fétidas, con laminación algal, que solo llevan pequeños lingúlidos. En bancos similares (con laminación peor conservada) abunda una fauna monoespecífica de pequeños bivalvos ("Nuculites"). Ambos tipos de roca se hallan, en las tres áreas, retrabajados como cantos blandos, y las laminitas se han resedimentado en algunos niveles como placas delgadas, peladas por desecación y hasta teñidas de rojo (en la DARC). Además, se intercalan frecuentes paleocanales pequeños en las capas lutíticas. Todo esto demuestra somerizaciones extremas, que causan la ausencia o la baja diversidad de las faunas. La asociación usual en tramos con paleocanales consiste en Mauispirifer, Plebejochonetes, tentaculítidos y ostrácodos; pero en la DARC se intercala, en la parte alta de la unidad d2c $\alpha 5$, también un tramo de $2 \mathrm{~m}$ con calizas de braquiópodos con cierta diversidad (incluso primeros hallazgos del grupo de "Spirifer" rousseaui Rouault), que parece tener su equivalente en la unidad MS12f en el GU. A pesar de los diferentes espesores (GU cerca de $100 \mathrm{~m}$, NI unos $60 \mathrm{~m}$, DARC $18 \mathrm{~m}$ ), los intervalos con múltiples somerizaciones en las tres áreas presentan una notable uniformidad en
Celtiberia. También en Armórica se reconoce este intervalo como parte media de un tramo regresivo. (Cortes de l'Armorique cerca de Brest, según los conodontos debajo de los niveles S145 y N54; ver Pelhate en Plusquellec (Ed.), 1980: Fig. 8, Lám. 6, Fig. 4.)

El régimen de somerizaciones se termina en toda Celtiberia (incluso en HEN, donde faltan aún informaciones detalladas sobre los intervalos inferiores) pocos decímetros por debajo del límite entre los paquetes $\mathrm{d} 2 \mathrm{c} \alpha$ y d2c $\beta$. Este límite se registra en los cortes gracias a un cambio de bancos de calizas algo arenosas y de un último banco de arenisca hacia caliza margosa sin arena. En DARC, HEN, NI y GU entra, inmediatamente debajo del límite, I. s. simulator Carls. La misma marca bioestratigáfica se halla en el oeste de Armórica (cortes de l'Armorique S145 y N54), pero allí se prolonga la tendencia regresiva aún unas docenas de metros encima de ella.

Después de la tendencia regresiva, se instala en el paquete $\mathrm{d} 2 \mathrm{c} \beta$ de la DARC, que es una alternancia de lutitas finas y calizas margosas (unos $40 \mathrm{~m}$ ), una facies favorable para faunas diversas de braquiópodos, en gran parte clarícolas, trilobites (Pseudocryphaeus, Parahomalonotus, escasos "Phacops"), ostrácodos, algunos bivalvos (Actinopteria), briozoos fenestélidos y otros, rugosos solitarios, tabulados masivos y ramiformes y cefalópodos ortocónicos. Se trata del intervalo con dominancia del grupo de "Spirifer" rousseaui. En NI existe una facies comparable pero no bien conservada. En HEN se halla poco evolucionada. En el GU se formaron calizas algo fétidas en bancos gruesos (MS13, $50 \mathrm{~m}$ ), de los cuales sólo algunos contienen los braquiópodos y trilobites de la misma fauna. A pesar de las variaciones en Celtiberia, se encuentran facies similares a la de la DARC en las áreas cantábricas y hasta tan lejos como en el este de Armórica, en las famosas localidades de la Baconnière, de l'Asnerie, etc. También la continuación de la sucesión en las lutitas de la parte inicial de la Fm. Santa Cruz en la DARC tiene su equivalente en la parte baja de la Fm. Montguyon en Armórica oriental.

\section{CONCLUSIONES}

Las sucesiones estratigráficas del Pridoliense y del Devónico de Ibero-Armórica muestran ritmicidades notables; se han analizado los ritmotemas en Celtiberia hasta el Praguiense temprano. Aunque la formación de unidades siliciclásticas dependía esencialmente de los aportes y de las áreas-fuente, que deberían de ser diferentes entre sí, los niveles de cuarcitas maduras en el Pridoliense y Lochkoviense temprano exhiben la mayor uniformidad de facies y fauna. En el Lochkoviense tardío y Praguiense inicial se establecieron mayores diferencias laterales, cuando los aportes de limos y arenas menos maduras cubrieron sólo áreas menores. La mayor contribución de las faunas a la producción de sedimento no condujo a la uniformidad en este intervalo, sino que aumentó las diferencias. Con la somerización, que se registra poco después de la entrada de Mauispirifer en 
alternancias de lutitas con calizas y margas, vuelve una fase de uniformidad. Muchos pulsos de la ritmicidad resultan ser locales; hasta los de mayor extensión horizontal no se dejan correlacionar con los pulsos T-R que actualmente se cree que son de relevancia global, porque los cambios registrados en Celtiberia son más numerosos que las oscilaciones en las curvas T-R y porque los indicadores de la zonación de conodontos, que se utilizan para la identificación de las oscilaciones supuestamente globales, no son suficientes para la discriminación de sucesos ligeramente heterocrónicos. Este resultado obtenido en las sucesiones estratigráficas con la subdivisión natural más detallada del Devónico Inferior en Europa reduce las esperanzas acerca de una estratigrafía secuencial con marcas isócronas válidas a escala suprarregional para el intervalo estudiado.

\section{AGRADECIMIENTOS}

Este trabajo es un resultado de la colaboración de ambos autores financiada por la Fundación Alexander von Humboldt y constituye una contribución al proyecto IGCP 421. Rosa Ma Martínez González, Sonia Ros y Hector Botella colaboraron en parte de las labores de campo realizadas en Nigüella. Agradecemos de corazón la paciencia, tiempo y, en particular, los comentarios y correcciones de Jenaro García-Alcalde y Susana GarcíaLópez (Oviedo).

\section{BIBLIOGRAFÍA}

Aldaya, F., Carls, P., Martínez-García, E. et Quiroga, J.L. 1976. Nouvelles précisions sur l'age de la serie de San Vitero (Zamora, Nord-Ouest de l'Espagne). Comptes Rendus de l'Académie des Sciences, Paris (Serie D), 283, 881-883.

Babin, C., Deunff, J., Melou, M., Paris, F., Pelhate, A., Plusquellec, Y. et Racheboeuf, P. R. 1979. La Coupe de Porz ar Vouden (Pridoli de la Presqu'ile de Crozon) Massif Armoricain, France Lithologie et Biostratigraphie. Palaeontographica A, 164, 52-84.

Bultynck, P. 1971. Le Silurien supérieur et le Dévonien inférieur de la Sierra de Guadarrama (Espagne centrale). Deuxième partie: Assemblages de Conodontes à Spathognathodus. Bulletin de l'Institut royal des Sciences naturelles de la Belgique, 47 (3), 212-230.

Bultynck, P. et Pelhate, A. 1971. Découverte de la zone à eoesteinhornensis (Conodontes) dans le Synclinorium Médian du Massif Armoricain. Colloque OrdovicienSilurien, Brest. Memoires du B.R.G.M., 73, 189-198.

Bultynck, P. et Soers, E. 1971. Le Silurien supérieur et le Dévonien inférieur de la Sierra de Guadarrama (Espagne centrale). Prémière partie: Stratigraphie et tectonique. Bulletin de l'Institut royal des Sciences naturelles de la Belgique, 47 (7), 1-22.

Carls, P. 1969. Die conodonten des tieferen Unter-Devons der Guadarrama (Mittel Spanien) und die Stellung des Grenzbereiches Lochkovium/Pragium nach der rheinischen Gliederung. Senckenbergiana lethaea, 50, 303-355.

Carls, P. 1971. Stratigraphische Übereinstimmungen im höchsten Silur und tieferen Unter-Devon zwischen Keltiberien (Spanien) und Bretagne (Frankreich) und das Alter des Grès de Gdoumont (Belgien). Neues Jahrbuch für Geologie und Paläontologie Monatshefte, 1971 (4), 195-212.

Carls, P. 1974. Die Proschizophoriinae (Brachiopoda; Silurium-Devon) der Östlichen Iberischen Ketten (Spanien). Senckenbergiana lethaea, 55, 153-227.

Carls, P. 1975. Zusätzliche Conodonten-Funde aus dem tieferen Unter-Devon Keltiberiens (Spanien). Senckenbergiana lethaea, 56, 399-428.

Carls P. 1977. The Silurian-Devonian boundary in northeastern and central Spain.- In: The SilurianDevonian Boundary (Ed. A. Martinsson). International Union of Geological Sciences, (A), 5, 143-158.

Carls, P. 1983. La Zona Asturoccidental-Leonesa en Aragón y el Macizo del Ebro como prolongación del Macizo Cantábrico. In: Libro Jubilar J.M. Ríos, 3. (Coord. J. A. Comba). I.G.M.E., Madrid, 11-32.

Carls, P. 1985. Howellella (Hysterohowellella) knetschi (Brachiopoda, Spiriferacea) aus dem tiefen UnterGedinnium Keltiberiens. Senckenbergiana lethaea, 65 , 297-326.

Carls, P. 1987. Ein Vorschlag zur biostratigraphischen Redefinition der Grenze Gedinnium/Siegenium und benachbarter Unter-Stufen. Courier Forschungs-Institut Senckenberg, 92, 77-121.

Carls, P. 1988. The Devonian of Celtiberia (Spain) and Devonian paleogeography of SW Europe. In: Devonian of the World (Eds. H.J. McMillan, A.F. Embry and D.J. Glass). Canadian Society for petroleum geology, Calgary, 14 (1), 421-466.

Carls, P. und Gandl, J. 1969. Stratigraphie und Conodonten des Unter-Devons der Östlichen Iberischen Ketten (NE Spanien). Neues Jahrbuch für Geologie und Paläontologie Abhandlungen, 132 (2), 155-218.

Carls, P., Meyn, H. und Vespermann, J. 1993. Lebensraum, Entstehung und Nachfahren von Howellella (Iberohowellella) hollmanni n. sg. n. sp. (Spiriferacea; Lochkovium, Unter-Devon). Senckenbergiana lethaea, 73, 227-267.

Franke, W. und Oncken, O. 1995. Zur prädevonischen Geschichte des Rhenohercynischen Beckens. Nova Acta Leopoldina, Neue Folge, 71 (291), 53-72.

Gandl, J. 1972. Die Acastavinae und Asteropyginae (Trilobita) Keltiberiens (NE-Spanien). Abhandlungen der senckenbergischen naturforschenden Gesellschaft, 530, 1-184.

Henn, A. und Jahnke, H. 1984. Die Palentinische Faziesentwicklung im Devon des Kantabrischen Gebirges. Zeitschrift der deutschen geologischen Gesellschaft, 135, 131-147.

Jahnke, H., Henn, A., Mader, H. und Schweineberg, J. 1983. Silur und Devon im Arauz-Gebiet (Prov. Palencia, NSpanien). Newsletters on Stratigraphy, 13 (1), 40-66.

Lotze, F. 1929. Stratigraphie und Tektonik des Keltiberischen Grundgebirges (Spanien). Abhandlungen 
der Gesellschaft der Wissenschaften, Göttingen, mathematisch-physikalische Klasse, neue Folge, 14 (2), 1-320.

Lotze, F. 1945. Zur Gliederung der Varisziden der Iberischen Meseta. Geotektonische Forschungen, 6, 7892.

Mader, H. 1986. Schuppen and Zähne von Acanthodiern und Elasmobranchiern aus dem Unter-Devon Spaniens (Pisces). Göttinger Arbeiten zur Geologie und Paläontologie, 28, 1-59.

Morzadec, P. et Paris, F. 1976. Confrontacion des données et comparaisons avec des successions éodévoniennes d'Europe et d'Afrique du Nord. In: Les Schistes et calcaires eodevonies de Saint-Céneré (Massif Armoricain, France) sédimentologie, paléontologie, stratigraphie (Ed. H. Lardeux). Mémoires de la Société géologique et minéralogique de Bretagne, 19, 7-14.

Nikiforova, O.J. 1977. Podolia. In: The Silurian-Devonian Boundary (Ed. A. Martinsson). International Union of Geological Sciences, (A), 5, 52-64.

Plusquellec, Y. (Ed.) 1980. Les Schistes et calcaires de l'Armorique (Dévonien inférieur, Massif Armoricain). Mémoires de la Societé géologique et minéralogique de Bretagne, 23, 1-317.

Racheboeuf, P. 1981. Chonétacés (brachiopodes) siluriens et dévoniens du Sud-ouest de l"Europe. Mémoires de la Societé géologique et minéralogique de Bretagne, 27, 1294.

Sommer, W. 1965. Stratigraphie und Tektonik im östlichen Guadarrama-Gebirge (Spanien). Arbeiten aus dem Geologisch-Paläontologischen Institut der Westfälischen Wilhelms-Universität zu Münster, 1, 1-169.

Uyeno, T.T. 1980. Stratigraphy and conodonts of Upper Silurian and Lower Devonian rocks in the environs of the Boothia uplift, Canadian Arctic Archipelago. Part II Systematic study of conodonts. Geological Survey of Canada Bulletin, 292, 39-75.

Valenzuela-Ríos, J. I. 1984. Estudio geológico de un sector de las Cadenas Ibericas Orientales entre Minas Tierga, Mesones y Nigüella (Zaragoza). Tesis de Licenciatura (inédita), Universidad de Zaragoza, $132 \mathrm{pp}$.

Valenzuela-Ríos, J. I. 1989. El Paleozoico de Nigüella (nota preliminar). Azara, 1, 35-43.

Valenzuela-Ríos J.I. 1994. Conodontos del Lochkoviense y Praguiense (Devónico Inferior) del Pirineo Central Español. Memorias del Museo Paleontológico de la Universidad de Zaragoza, 5, 1-178.

Valenzuela-Ríos J.I. and Murphy, M. 1997. A new zonation of middle Lochkovian (Lower Devonian) conodonts and evolution of Flajsella n. gen. (Conodonta). In: Paleozoic Sequence Stratigraphy and Biogeography: Studies in Honor of J. Granville ("Jess") Johnson (Eds. G. Klapper, M.A. Murphy and J.A. Talent). Geological Society of America Special Paper, 321, 131-144.

Viallard, P. 1973. Recherches sur le Cycle Alpin dans la Chaine Iberique sud-occidentale. Travaux $d u$ Laboratoire de Geologie Mediterraneenne Associe au C.N.R.S. Universite Paul Sabatier-Toulouse, 577, 1-445.

Walliser, O. 1964. Conodonten des Silurs. Abhandlungen hessisches Landesamt Bodenforschung, 41, 1-106.

Wang, R.H. 1993. Taxonomie, Palökologie und Biostratigraphie der Mikroichthyolithen aus dem Unterdevon Keltiberiens, Spanien. Courier Forschungsinstitut Senckenberg, 161, 1-205.

Ziegler, P. 1988. Laurussia - the Old Red Continent. In: Devonian of the World (Eds. H.J. McMillan, A.F. Embry and D.J. Glass). Canadian Society for petroleum geology, Calgary, 14 (1), 15-48. 